\title{
Treatment of Crohn's Fistulae Using an Anal Fistula Plug of Porcine Small Intestinal Submucosa Origin
}

\author{
Alex J. Ky*,1, Beth Moore ${ }^{2}$, Phil Fleshner ${ }^{2}$, R. David Hucks ${ }^{3}$ and Jason P. Hodde ${ }^{3}$ \\ ${ }^{1}$ Mount Sinai Medical Center, One Gustave L. Levy Place, New York, NY 10029, USA \\ ${ }^{2}$ Cedars-Sinai Medical Center, 8700 Beverly Blvd., Los Angeles, CA 90048, USA \\ ${ }^{3}$ Cook Biotech Inc., 1425 Innovation Place, West Lafayette, IN 47906, USA
}

\begin{abstract}
Objective: This study was designed to evaluate the efficacy of the Biodesign ${ }^{\circledR}$ Anal Fistula Plug (AFP) for the closure of Crohn's anorectal fistula.

Patients \& Methods: This study was a prospective analysis of patients with Crohn's disease who received the AFP for the treatment of anorectal fistulas of Crohn's origin. Under general anesthesia and in the lithotomy or prone jackknife position, patients underwent irrigation of the fistula tract by saline or hydrogen peroxide. The AFP was then inserted into the fistula tract until it was snug. The internal end of the plug was securely sutured with 2-0 Vicryl ${ }^{\circledR}$ and covered with a small mucosal advancement flap, while the external opening was left open to allow for drainage.

Results: Twenty-one patients with a combined 28 fistula tracts were prospectively enrolled. Three single tract fistula patients were lost to follow up and were excluded from the analysis. At the final follow-up of 12 months, all fistula tracts were successfully closed in 10 of 18 patients, for an overall success rate of 56\%; total fistula tracts were closed in 17 of 25 tracts, for an overall success rate of $68 \%$. None of the tracts that were closed recurred during the study period.

Conclusions: Closure of Crohn's anorectal fistulas using the anal fistula plug is safe and successful in 56\% of patients and $68 \%$ of fistula tracts. Given the relatively low morbidity associated with the procedure, the AFP should be considered as a viable treatment option for patients with Crohn's-associated anorectal fistulas.
\end{abstract}

Keywords: Crohn's disease, fistula, anal fistula plug.

\section{INTRODUCTION}

The surgical treatment of Crohn's anorectal fistulas is extremely challenging with variable results. Fistulotomy has been well established as the treatment of choice for most simple, superficial fistulas, but these represent a minority of Crohn's fistulas. Fistulotomy also carries significant risks of pain, non-healing wounds, and incontinence. Alternative treatment options, including dermal or endorectal advancement flaps, have been employed with variable success, but these can be technically challenging and also carry considerable postoperative risks. Fibrin sealant injection has been demonstrated to be effective, with essentially no risk of incontinence; however, success rates are usually reported to be between $10-60 \%$ [1, 2]. This dilemma has led to the search for novel treatment options.

Recent evidence supports the use of Biodesign ${ }^{\circledR}$ AFP (Anal Fistula Plug; Cook Medical, Bloomington, IN) for the repair of complex anal fistulas, although the reported success rates vary widely [3-7]. Biodesign is a bioprosthetic material derived from porcine small intestinal submucosa (SIS) that

*Address correspondence to this author at the Mount Sinai Medical Center One Gustave L. Levy Place, New York, NY 10029, USA; Tel: (917) 576-2323; Fax: (212) 534-2654;

E-mail: Alex.Ky@msnyuhealth.org has been successfully used for a variety of surgical indications. The Biodesign AFP actively facilitates the remodeling of host tissue at the injury site. The plug is implanted into the fistula tract and sutured securely to the primary opening. SIS is engineered to promote tissue remodeling while being slowly incorporated into the body during a three-month to six-month period [8-11]. Therefore, SIS provides mechanical integrity while acting as a scaffold to guide tissue incorporation.

In a clinical study which compared a rolled Biodesign sheet to fibrin glue for treatment of high transsphincteric fistulas, Johnson et al. [4] found that six of ten (60\%) experienced continued fistula persistence at three months after fibrin glue treatment, in contrast to 2 of 15 patients (13\%) treated with the anal fistula plug. A separate report documented successful closure in $83 \%$ of fistula tracts (30 of 36) in patients with Crohn's disease [5]. Failure of the tract to close was significantly associated with the presence of multiple fistula tracts - a difficult but common treatment scenario in this patient population. Additionally, the safety and medium-term (10-12 months) efficacy of the Biodesign AFP has also been reported [6, 7]. In a previous prospective study, we reported successful closure in $55 \%$ of patients with a mean follow-up of 6.5 months [12]. In the current study, we evaluated the efficacy of the AFP in multiple patients with a 
Crohn's Disease diagnosis and present these clinical results along with clinical observations from our experience.

\section{PATIENTS AND METHODS}

This study was approved by the local Institutional Review Boards and was listed in a publically-accessible database as required. The unique identifying number, NCT00610207, was assigned. All subjects presenting with anorectal fistulas and a diagnosis of Crohn's Disease were offered participation in the study and, after providing informed consent, were enrolled prospectively to receive the Biodesign AFP. The study was conducted between October 2006 and August 2008. Patients with co-morbidities, including HIV, autoimmune disease, active malignancy, diabetes, and/or a history of pelvic radiation were also offered participation, as were patients with multiple and/or recurrent fistula tracts. All patients were treated with a standardized clinical protocol. The Wexner Fecal Incontinence Score was conducted preoperatively and at one and three months postoperatively.

The procedure was performed as an outpatient surgery. Patients were asked to administer an enema for preoperative bowel preparation at home the morning of their scheduled surgery. They were then admitted to the hospital or outpatient surgical center the morning of the surgery where they met with an anesthesiologist. A single peri-operative dose of intravenous antibiotics was administered and the patient received either spinal or general anesthesia. The patient was then placed in the lithotomy or prone jackknife position.

\section{Biodesign AFP Insertion Technique}

The anal fistula was carefully identified, and if the internal opening was difficult to find the tract was irrigated with saline or hydrogen peroxide. No mechanical debridement of the tract was performed. A probe was then passed through the fistula and a suture was dragged through the tract by the probe. The suture was then secured to the Biodesign AFP, which was pulled through the tract from the internal orifice towards the external orifice. The Biodesign AFP is conical, and the wider aspect of the plug was placed on the mucosal side of the fistula. The plug was pulled through the tract until it was snug within the fistula, and then was trimmed at the level of the internal and external openings. The internal end of the plug was securely sutured to the anorectal wall with 2$0 \mathrm{Vicryl}^{\circledR}$, and then the rectal mucosa was closed over the plug to completely bury it. The external opening was left open to drain any residual contents of the tract. Patients were then brought to the recovery room where they were monitored until their condition satisfied the criteria for discharge home.

\section{Postoperative Care}

Postoperatively, patients were placed on a stool-softening diet and were instructed not to have strenuous activity or sexual intercourse for at least two weeks. They were instructed to shower for the first two days and then to start sitz baths after postoperative Day 2. Patients received seven days of prophylactic oral ciprofloxacin and metronidazole and were instructed to apply topical metronidazole cream to the external opening daily for seven days. Follow-up consisted of initial office evaluation at 2, 4, 8 and 12 weeks postoperatively for tract closure and complications, with additional follow-up at 6 and 12 months.

\section{RESULTS}

\section{Demographics}

Twenty-one subjects who were diagnosed with Crohn's Disease underwent AFP placement for treatment of anal fistulas between October 2006 and August 2008. Six subjects were on active anti-TNF medication and three subjects were

Table 1. Patient Characteristics

\begin{tabular}{|c|c|}
\hline Age & 40.2 (range, 22-69) \\
\hline M:F & $9: 9$ \\
\hline Height & 66 ” (range, 59”- 72”) \\
\hline Weight & 148 pounds (range 85-208) \\
\hline BMI & 24 (range 14-37) \\
\hline Number of fistulas/plugs & 25 \\
\hline Patients with Multiple Tracts & 5 \\
\hline
\end{tabular}

Table 2. \# of Tracts Closed Over Time

\begin{tabular}{|c|c|c|c|c|c|c|c|}
\hline Follow Up & 2 Weeks & 4 Weeks & 6 Weeks & 8 Weeks & 12 Weeks & 6 Months & 12 Months \\
\hline \hline Tracts first closed at each time point & 0 & 5 & 0 & 5 & 2 & 3 & 2 \\
\hline Total cumulative tracts closed & 0 & 5 & 5 & 10 & 12 & 15 & 17 \\
\hline Cumulative closure rate (\%) & $0 \%$ & $20 \%$ & $20 \%$ & $40 \%$ & $48 \%$ & $60 \%$ & $68 \%$ \\
\hline
\end{tabular}


undergoing current steroid therapy. Three single-tract fistula patients were lost to follow-up and were excluded from the analysis. Therefore, 12 month follow-up was available for 18 subjects of whom 9 were male and 9 were female. Average age was 40.2 (range, 22-69 years). There were 5 patients with two or more fistula tracts and 13 patients with one fistula tract. Three patients with two or more fistula tracts had 10 plugs placed in separate tracts. Of the two remaining patients with multiple tracts, one patient underwent plug placement in one tract and a seton/fistulotomy in a second tract, while the other underwent plug placement in one tract and was treated with an advancement flap in the second tract (Table 1).

\section{Outcomes of Biodesign AFP Placement}

Follow-up information was available for 25 AFP's in 18 different patients. The primary endpoint of the study was fistula closure as assessed at 2, 4, 8, and 12 weeks postoperatively, with additional follow-up at 6 and 12 months (Table 2). A secondary endpoint was a change in the fecal incontinence score. At the final 12-month follow-up, all fistula tracts were successfully closed in 10 of 18 (56\%) patients, and in 17 of 25 tracts, for an overall success rate of $68 \%$. None of the tracts that were closed recurred during the study period.

Early plug failures occurred in 3 patients (17\%). These were identified within the first 3 months postoperative and were all characterized by abscesses requiring drainage $(n=3)$. Clinical evaluation at the 3 month postoperative visit revealed an additional 5 patients (28\%) with plug failures manifesting as persistent drainage or granulation tissue at the external opening.

The type of fistulas treated with the AFP were rectovagi-

Table 3. Tract Type and Effect on Outcome

\begin{tabular}{|c|c|c|}
\hline Description & Healed & Not Healed \\
\hline \hline Rectovaginal & 1 & 0 \\
\hline Extrasphincteric & 3 & 0 \\
\hline Suprasphincteric & 2 & 6 \\
\hline Transphincteric & 10 & 1 \\
\hline Intersphincteric & 1 & 8 \\
\hline Total & 17 & 0 \\
\hline
\end{tabular}

Table 4. Significance of Abscess on Outcome

\begin{tabular}{|c|c|c|c|}
\hline & Healed & Not Healed & $\mathbf{p}^{*}$ \\
\hline \hline Abscess & 0 & 3 & 0.024 \\
No Abscess & 17 & 5 & \\
\hline
\end{tabular}

* 2-tailed Fisher's Exact Test

Table 5. Significance of Multiple Tracts on Outcome

\begin{tabular}{|c|c|c|c|}
\hline & Healed & Not Healed & p $^{*}$ \\
\hline \hline Single Tract & 7 & 6 & 0.202 \\
\hline Multiple Tracts & 10 & 2 & \\
\hline * 2-tailed Fisher's Exact Test & & 2 \\
\hline
\end{tabular}

Table 6. Tract Length and Outcomes

\begin{tabular}{|c|c|c|}
\hline Tract Length & Healed & Not Healed \\
\hline \hline $1-2 \mathrm{~cm}$ & 0 & 0 \\
\hline $2-3 \mathrm{~cm}$ & 10 & 4 \\
\hline $3-4 \mathrm{~cm}$ & 2 & 2 \\
\hline $4-5 \mathrm{~cm}$ & 4 & 0 \\
\hline $5-6 \mathrm{~cm}$ & 1 & 2 \\
\hline
\end{tabular}


Table 7. Significance of Tract Length on Outcome

\begin{tabular}{|c|c|c|c|}
\hline Tract Length & Healed & Not Healed & $\mathbf{p}^{*}$ \\
\hline$<4 \mathrm{~cm}$ & 12 & 6 & 1 \\
\hline$>4 \mathrm{~cm}$ & 5 & 2 & \\
\hline
\end{tabular}

* 2-tailed Fisher's Exact Test

Table 8. Significance of Gender on Outcome

\begin{tabular}{|c|c|c|}
\hline Results & Male & Female \\
\hline \hline Healed & 12 & 5 \\
\hline Not Healed & 2 & 6 \\
\hline $\mathrm{p}^{*}$ & & 0.081 \\
\hline
\end{tabular}

nal in 2 (8\%) tracts, extrasphincteric in 3 (12\%) tracts, suprasphincteric in 2 (8\%) tracts, transphincteric in 16 (64\%) tracts, and intersphincteric in 2 (8\%) tracts. Fistulas were classified as complex in $9(36 \%)$ tracts, horseshoe in $1(4 \%)$ tract, and radial in 15 (60\%) tracts (Table 3).

Plug success was 54\% among the 13 patients presenting with a single fistula tract compared with $80 \%$ in the 5 patients with two or more fistula tracts $(p=0.694$, 2-tailed Fisher's Exact Test). Presence of an abscess was associated with failure (Table 4), and the presence of multiple tracts in a patient was not significant (Table 5). Shorter tracts appeared more likely to heal (Table 6 and Table 7), and more tracts healed in men than in women (Table 8) although study power was insufficient to detect a significant difference statistically.

The average time spent in the operating room was 25 minutes (range, 5-50). The average length of each fistula tract was $3.2 \mathrm{~cm}$ (range, $1.0 \mathrm{~cm}-6.0 \mathrm{~cm}$ ). There were no changes in the Wexner Fecal Incontinence Score in any of the patients (data not shown).

In summary, in this series of 18 patients diagnosed with Crohn's associated anal fistulas, 10 patients healed with the AFP procedure leading to a cure of $56 \%$ without continence impairment. Seventeen fistula tracts out of 25 were closed for an overall success rate of $68 \%$.

\section{DISCUSSION}

The treatment of anal fistulas in patients with Crohn's Disease remains a challenging clinical problem. Fistulotomy, although associated with healing rates ranging from 62$100 \%$ in Crohn's fistulas and recurrence rates ranging from $0-17 \%$ in complex fistulas, has a relatively high risk of incontinence. The placement of setons is useful for the challenge of recurring abscess formation; however, persistent drainage from persistent tracts diminishes the patient's quality of life. Advancement flap procedures are another option for fistula treatment with success rates ranging from 55-98\%; however, the incidence of major incontinence as high as $12 \%$ is still reported [13]. Incontinence and invasiveness of these procedures, especially in the Crohn's population, have prompted the search for novel treatment options.
The Biodesign AFP was developed as an alternative for the treatment of anal fistulas as a means to close the primary fistula opening. Made from the submucosal tissue layer of porcine small intestine, the AFP is a biologic material with inherent resistance to infection that has been successful after implantation into contaminated surgical fields [14-16]. When the AFP is placed into the primary opening of a fistula, it occludes the tract without requiring sphincter division, thus eliminating the risk of subsequent incontinence. Additionally, the surgical procedure to place the plug is non-invasive and minimizes the risks of surgical intervention in the Crohn's population, and has demonstrated effectiveness in 75\% of Crohn's-related fistulas with 9 month follow-up [17]. Our current findings further support the effectiveness of the AFP in the Crohn's population.

Technically, implantation of the plug is a simple procedure that requires only a minimal amount of operating room time. However, care needs to be taken to insure that the plug is firmly secured to the internal sphincter muscle. If not adequately secured, the mechanical pressures within the anal canal can dislodge the plug, leading to early extrusion [6, 13]. Our current study supports minimal operating time in that averages of 25 minutes (range, 5-50) were spent in the operating suite.

We found that all fistula tracts had been successfully closed in $56 \%$ of evaluable patients and in $68 \%$ of evaluable tracts. The rate of plug success was $54 \%$ among 7 of the 13 patients with a single fistula tract compared with $80 \%$ in 4 of the 5 patients with two or more fistula tracts. Although not statistically significant, our findings that multiple fistula tracts healed at a higher rate than single fistula tracts are interesting because previously-published Crohn's fistula studies indicate that patients with multiple fistula tracts have a significantly higher failure rate because of persistence of one or more tracts [5]. Patients with multiple fistula tracts with anorectal Crohn's disease represent the most difficult surgical challenge in an intensely difficult disease process. Further evaluation in a larger patient population is warranted to study the effects of long term AFP healing rates in patients with multiple fistula tracts as compared to single fistula tracts. 
Early failure occurred in the 3 patients in whom abscess formation was described. Because the AFP consists of noncrosslinked extracellular matrix, it is susceptible to breakdown by proteases secreted by some different strains of some anaerobic bacteria species. While it is commonly known that all fistula tracts are colonized by bacteria, care should be taken to avoid plug placement in tracts that are characterized by active infection or abscess. In our study we required the tract to be mature without signs of active infection or inflammation. Additionally, the tracts should be cleaned prior to placement of the plug with hydrogen peroxide to further reduce the bacterial load. In this series, the development of an abscess led to failure of all plugs placed, suggesting that the prevention of abscess is very important to ensure plug success. While all patients treated were free of any visible abscess or active infection prior to plug placement, it is theoretically possible that the tracts in these patients were sub-clinically colonized at the time of placement and that the occlusion of the tract with the plug allowed an abscess pocket to form.

A recent study reported that tract length predicts the outcome of AFP placement [18]. In that report, tracts that were $4 \mathrm{~cm}$ in length or longer were 3 times more likely to heal than tracts that were less than $4 \mathrm{~cm}$ in length (61\% vs. $21 \%)$. Although not significant, it is compelling that our study indicates the opposite; a greater number of tracts healed that were less than $4 \mathrm{~cm}$ in length ( $48 \%$ vs. $20 \%$ ).

We also looked at the effect of gender on predicting AFP success. In our series, there were 14 (56\%) tracts in males and $11(44 \%)$ tracts in females. In contrast to results reported by others [18], more tracts healed in men than in women, supporting the literature that suggests that complex tracts, such as anterior fistula tracts in women, are notoriously difficult to heal [19]. Clearly, the disparate results published in the literature on the efficacy of the AFP may need to take gender, as well as tract length, into consideration when predicting best outcomes and choosing the ideal patient for the placement of the plug.

Since the beginning of this prospective study, a consensus conference was held to document how to best use the AFP for treatment of anorectal fistulas [20] and techniques have been suggested to optimize results. In this study for example, we did not routinely debride the tract neither with hydrogen peroxide nor mechanically. It is now thought that mechanical debridement of the tract is necessary for good plug incorporation, especially since literature suggests that at least some anal fistula tracts may be epithelialized [21]. Furthermore, other authors have advocated the widening of the external opening following placement of the plug to ensure adequate drainage and prevent abscess formation [22]. While we mobilized a small flap of mucosa over the head of the plug to ensure that the plug was completely buried under the rectal mucosa, this practice was not routinely recommended at the time the study commenced. It is unknown if the favorable results we saw in this series were related to this practice. Likewise, the post-operative practice of using topical metronidazole over the external opening has been debated; at this time, it is unknown if this practice results in any substantial benefit.

\section{CONCLUSIONS}

Closure of Crohn's anorectal fistulas with the Biodesign AFP is a safe and effective alternative to other more invasive surgical approaches. The AFP avoids the risk of incontinence and is not associated with other complications. Given the relatively low morbidity associated with the procedure, the anal fistula plug should be considered as a viable treatment option for patients with anorectal fistulas arising from Crohn's Disease.

\section{DISCLAIMERS} Inc.

D. Hucks and J. Hodde are employees of Cook Biotech Study was funded by Cook Biotech Inc.

Other authors have no additional relationships with Cook Biotech Inc.

\section{ACKNOWLEDGEMENTS}

None declared.

\section{CONFLICT OF INTEREST}

The authors confirm that this article content has no conflicts of interest.

\section{REFERENCES}

[1] Damin DC, Rosito MA, Contu PC, Tarta C. Fibrin glue in the management of complex anal fistula. Arq Gastroenterol 2009; 46: 300-3.

[2] Cirocchi R, Farinella E, La Mura F, et al. Fibrin glue in the treatment of anal fistula: a systematic review. Ann Surg Innov Res 2009; 3: 12.

[3] Garg P, Song J, Bhatia A, Kalia H, Menon GR. The efficacy of anal fistula plug in fistula-in-ano: a systematic review. Colorectal Dis 2010; 12(10): 965-70.

[4] Johnson EK, Gaw JU, Armstrong DN. Efficacy of anal fistula plug vs. fibrin glue in closure of anorectal fistulas. Dis Colon Rectum 2006; 49: 371-6.

[5] O’Connor LM, Champagne BJ, Ferguson MA, Orangio GR, Schertzer ME, Armstrong DN. Efficacy of anal fistula plug in closure of Crohn's anorectal fistulas. Dis Colon Rectum 2006; 49: 1569-73.

[6] Champagne BJ, O’Connor LM, Ferguson MA. Orangio GR, Schertzer ME, Armstrong DN. Efficacy of anal fistula plug in closure of cryptoglandular fistulas: long-term follow-up. Dis Colon Rectum 2006; 49: 1817-21.

[7] Ellis CN. Bioprosthetic plugs for complex anal fistulas: an early experience. J Surg Educ 2007; 64: 36-40.

[8] Badylak SF. Small intestinal submucosal (SIS): a biomaterial conducive to smart tissue remodeling. In: Bell E, Ed. Tissue engineering: current perspectives. Cambridge: Berkhauser Publishers 1993; pp. 179-89.

[9] Badylak SF, Kropp B, McPherson T, Liang H, Snyder PW. Small intestinal submucosal: a rapidly resorbed bioscaffold for augmentation cystoplasty in a dog model. Tissue Eng 1998; 4: 379-87.

[10] Badylak SF. The extracellular matrix as a scaffold for tissue reconstruction. Semin Cell Dev Biol 2002; 13: 377-83.

[11] Badylak SF, Kokini K, Tullius B, Simmons-Byrd A, Morff R. Morphologic study of small intestinal submucosal as a body wall repair device. J Surg Res 2002; 103: 190-202.

[12] Ky AJ, Sylla P, Steinhagen R, Steinhagen E, Khaitov S, Ly EK. Collagen fistula plug for the treatment of anal fistulas. Dis Colon Rectum 2008; 51: 838-43. 
[13] Whiteford MH, Kilkenny $\mathrm{J} 3^{\text {rd }}$, Hyman $\mathrm{N}$, et al. The standards practice task force: the American society of colon and rectal surgeons. Practice parameters for the treatment of perianal abscess and fistula-in-ano (revised). Dis Colon Rectum 2005; 48: 1337-42.

[14] Helton WS, Fisichella PM, Berger R, Horgan S, Espat NJ, Abcarian $\mathrm{H}$. Short-term outcomes with small intestinal submucosal for ventral abdominal hernia. Arch Surg 2005; 140: 549-62.

[15] Ueno T, Pickett LC, de la Fuente SG, Lawson DC, Pappas TN. Clinical application of porcine small intestinal submucosal in the management of infected or potentially contaminated abdominal defects. J Gastrointest Surg 2004; 8: 109-12.

[16] Franklin ME Jr, Gonzales JJ Jr, Glass JL. Use of porcine small intestinal submucosal as a prosthetic device for laparoscopic repair of hernias in contaminated fields: 2-year follow-up. Hernia 2004; 8: 186-9.

[17] Schwandner O, Fuerst A. Preliminary results on efficacy in closure of transsphincteric and rectovaginal fistulas associated with
Crohn's disease using new biomaterials. Surg Innov 2009; 16: 1628.

[18] McGee MF, Champagne BJ, Stulberg JJ, Reynolds H, Marderstein E, Delaney CP. Tract length predicts successful closure with anal fistula plug in cryptoglandular fistulas. Dis Colon Rectum 2010; 53: $1116-20$

[19] Ellis CN, Rostas JW, Greiner FG. Long-term outcomes with the use of bioprosthetic plugs for the management of complex anal fistulas. Dis Colon Rectum 2010; 53: 798-802.

[20] [No authors listed]. The Surgisis AFP anal fistula plug: report of a consensus conference. Colorectal Dis 2008; 10: 17-20.

[21] Lunniss PJ, Sheffield JP, Talbot IC, Thomson JP, Phillips RK. Persistence of idiopathic anal fistula may be related to epitheliazation. Br J Surg 1995; 82: 32-3.

[22] Schwandner T, Roblick MH, Kierer W, Brom A, Padberg W, Hirschburger M. Surgical treatment of complex anal fistulas with the anal fistula plug: a prospective, multicenter study. Dis Colon Rectum 2009; 52: 1578-83.

(C) Ky et al.; Licensee Bentham Open.

This is an open access article licensed under the terms of the Creative Commons Attribution Non-Commercial License (http://creativecommons.org/licenses/by-nc/3.0/) which permits unrestricted, non-commercial use, distribution and reproduction in any medium, provided the work is properly cited. 